\title{
METODE REPOSISI ONSTREAM PIPA RAW WATER DENGAN BERBASIS STRESS ANALYSIS
}

\section{Onstream Reposition Method Of Raw Water Pipe Line Based on Stress Analysis}

\author{
(1) Sulardi \\ ${ }^{(1)}$ Sekolah Tinggi Teknonoli Minyak dan Gas Bumi Balikpapan \\ (1) Jln. Transad KM.8, Karang Joang, Balikpapan 76127 \\ ${ }^{(1)}$ Email : sulardikm61@yahoo.com
}

\begin{abstract}
Abstrak
Tujuan penelitian adalah untuk memberikan gambaran kondisi sub standard pipa air baku dan metode reposisi yang dilakukan dalam kondisi onstream. Metode penelitian yang digunakan adalah metode penelitian terpakai dan merupakan catatan success story pelaksanaan reposisi pipaair baku yang dilakukan pada kondisi onstream. Hasil penelitian menunjukan bahwa dengan pergeseran sejauh $180 \mathrm{Cm}$ maka pipa air baku berada pada kondisi sub standard dan unsafe condition. Metode reposisi yang dilakukan adalah dengan metode reposisi menggunakan temporary support, jidar ukur elevasi dan pengangkatan dengan chain block secara bertahap bertahap berdasarkan batas aman material pipa. Hasil penelitian menunjukan bahwa akibat pergeseran tersebut pipa mengalami over stress sehingga melebihi batas aman dan harus dilakukan reposisi keposisi dalam batas aman dengan metode pengangkatan. Hasil penelitian juga menunjukan bahwa metode pengangkatan berdasarkan batas aman tegangan terbukti cocok dan aman digunakan untuk mereposisi pipa air baku pada kondisi onstream. Keberhasilan penggunaan metode kerja ini juga telah direplikasi untuk melakukan pekerjaan sejenis di kilang PT. Pertamina RU V Balikpapan dan terbukti dapat menyelesaikan permasalahan dengan baik dan aman.
\end{abstract}

Kata kunci : Sub standard, reposisi onstream

\begin{abstract}
The purpose of the study was to provide an overview of the conditions of the standard substandard water pipes and repositioning methods carried out in onstream conditions. The research method used is the used research method and is a record of the success story of the implementation of raw pipe repositioning carried out on onstream conditions. The results of the study show that with a shift of $180 \mathrm{Cm}$ the raw water pipe is in sub standard and unsafe condition. The repositioning method is done by repositioning method using temporary support, elevation measurement and lifting with a gradual chain block based on the safe boundary of the pipe material. The results of the study show that due to this shift the pipe is over stressed so that it exceeds the safe limit and must be repositioned within the safe boundary with the lifting method. The research result also showed that the lifting method based on the safe voltage limit proved to be suitable and safe to use to reposition the raw water pipe in onstream conditions. The success of the use of this work method has also been replicated to carry out similar work at the PT. Pertamina RU V Balikpapan and proven to be able to solve problems well and safely.
\end{abstract}

Keywords: Sub standard, onstream reposition. 


\section{PENDAHULUAN}

Salah satu komponen penting pada unit pengolahan air (water treatment plant) adalah keresediaan air baku (raw water). Penyediaan air baku yang lokasi pengambilannya (feed intake) berada ditempat yang jauh dilakukan dengan alat pompa dan pengaliran dengan sistim perpipaan (pipe line). Demikian halnya kondisi proses yang terjadi pada sistim pengolahan air WTP Pancur yang mengambil air baku dari Waduk Wain dengan cara memompakan dan mengalirkannya dengan instalasi perpipaan sejauh 15 kilometer menuju ke unit water treatment (WTP) Pancur.

Permasalahan yang dihadapi adalah terjadinya pergeseran pipa diarea bangun bangunan waduk pengendali banjir (Bendali) Dahor sehingga instalasi perpipaan bergeser sejauh 180 $\mathrm{Cm}$ dari posisi semula sehingga kondisi pipa out of tolerance. Dengan hal tersebut dinyatakan bahwa pipa raw water pada kondisi sub standard dan unsafe condition.

Terhadap kondisi tersebut telah dilakukan upaya perbaikan dengan memasang penopang pipa sementara (temporary pipe support), namun upaya ini tidak berhasil dengan baik karena pergeseran pipa raw water masih tetap terjadi.

Untuk itulah penelitian ini penting untuk dilakukan dalam rangka menemukan jawaban atas permasalahan pergeseran pipa raw water dan metode reposisinya. Metode reposisi harus dilakukan pada kondisi pipa sedang beroperasi (onstream) untuk pemenuhan ketersediaan air untuk operasional kilang, kebutuhan domestic used, kebutuhan utilitas perkantoran.

Tujuan yang hendak dicapai dengan penelitian adalah :

1. Memberikan gambaran kondisi pipa raw water setelah mengalami pergeseran (terdeformasi)
2. Memberikan gambaran metode reposisi pipa raw water yang dilakukan pada kondisi onstream.

Untuk mencapai tujuan tersebut maka pada penelitian ini dikembangkan pertanyaan-pertanyaan penelitian sebagai berikut :

1. Bagaimana gambaran kondisi pipa raw water di area Bendali Dahor setelah mengalami pergeseran (terdeformasi)

2. Bagaimana gambaran metode reposisi pipa raw water yang dilakukan pada kondisi onstream.

Akibat terdeformasi maka pipa raw water mengalami tegangan berlebih (over stress), apabila tegangan terus bertambah akan mengakibatkan tegangan yang bekerja diluar batas aman (out of tolerance) dan dapat mengakibatkan pipa mengalami kegagalan (failure). Untuk itu pulalah maka diperlukan analisa stegangan (stress analysis) terhadap kondisi aktual setelah pipa raw water mengalami pergeseran dari posisinya (deformasi).

Piping Stress analysis adalah cara perhitungan tegangan (stress) pada pipa yang diakibatkan oleh beban statis dan beban dinamis yang merupakan efek resultan dari gaya gravitasi, perubahaan temperature, tekanan di dalam dan di luar pipa, perubahan jumlah debit fluida yang mengalir di dalam pipa dan pengaruh gaya seismic. Tujuan piping stress analysis adalah untuk mengetahui (1) keselamatan sistem perpipaan termasuk semua komponennya (2) keselamatan sistem peralatan yang berhubungan langsung dengan sistem perpipaan dan struktur bangunan pendukung sistem tersebut, dan (3) defleksi pipa agar tidak melebihi limitasinya. Perhitungan analisis tengangan pipa dilakukan untuk menjamin (to ensure) bahwa piping system beroperasi dengan aman tanpa mengalami kecelakaan. Dalam kenyataannya, piping system yang 
didalamnya mengalir fluida, baik panas, dingin akan mengalami pemuaian (expansion) atau pengkerutan (contraction) yang berakibat timbulnya gaya yang bereaksi pada ujung koneksi (connection), akibat dari temperature, berat pipa dan fluida didalam pipa. Piping system didisain se-flexible mungkin untuk menghindari pergerakan pipa (movement) akibat thermal expansion atau thermal contraction. Adanya ekspansi dan kontraksi secara berlebihan dapat mengakibatkan (1) kegagalan pada piping material karena terjadinya tegangan yang berlebihan atau overstress maupun fatigue (2) tegangan berlebihan pada pipe support atau titik tumpuan (3) kebocoran pada sambungan flanges maupun di valves (4) kerusakan material di nozzle equipment seperti pompa, tanki, bejana tejan, alat penukar panas (HE) akibat gaya dan moment yang berlebihan, serta (5) resonansi akibat terjadi vibration.

Asumsi penelitian adalah bahwa jika stress analysis piping system dapat diketahui maka dapat ditentukan metode reposisi yang cocok dan tepat digunakan seperti mereposisi peripaan dengan metode pengangkatan secara bersama-sama dan secara perlahanlahan sampai dengan batas aman tanpa terjadi tegangan yang berlebihan (over stress). Setelah pipa direposisi ke posisi aman kemudian perpipaan disupport dengan permanent support secara kokoh dan stabil agar dapat difungsikan kembali dengan baik dan aman (safe).

\section{METODE PENELITIAN}

\section{Metode Penelitian}

Metode penelitian ini metode penelitian aplikasi atau metode penelitian terpakai dengan pendekatan studi kasus, yakni kasus deformasi pipa raw water unit water treatment plant yang terjadi dilokasi pembangunan reservoir Waduk pengendali banjir (Bendali) Pertamina RU V di area Komperta Dahor.
Penelitian ini adalah technical notes succes story aplikasi metode reposisi pipa raw water Unit WTP Pertamina RU V. Metode reposisi pipa raw water ini menggunakan alat bantu gawang angkat (portal), alat angkat chain blok, alat bantu angkat websling, alat ukur water pass, jidar ukur elevasi, metode pengangkatan secara bertahap dengan tinggi pengangkatan $5 \mathrm{Cm}$ (5-10\% OD pipa) dan dilanjutkan dengan relaksasi (stress release) selama 5-10 menit setiap kali selesai pengangkatan.

\section{Bahan}

Spesifikasi material pipa raw water yang digunakan adalah API 5L dari pabrikan Shinestar group Bestar steel Vo,.Ltd, Jepang dengan Dimensi pipa. 16 Inch, Schedule Standard, Yield strength.363 Mpa, Tensile strength. 435Mpa dan Elongation Length. 36\%.

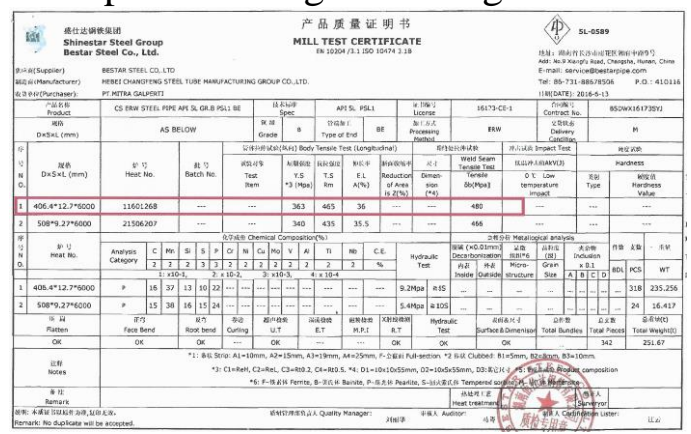

Gambar. 1

Mild test certificate API 5L

\section{Peralatan}

Peralatan yang digunakan untuk reposisi pipa raw water meliputi :

1. Gawang angkat (portal), dimensi menyesuaikan

2. Chain block, kapasitas angkat 10 tons, jumlah menyesuaikan

3. Alat kelengkapan pengangkatan (lifting devices), web sling kapasitas. 10 tons

4. Alat bantu pengangkatan (safety devices)

5. Alat ukur theodolite, water pass dan GPS

6. Leveling/ Jidar ukur 
7. Peralatan lain sesuai kebutuhan disite.

\section{Metode Pengangkatan Pipa}

1. Metode kerja persiapan dengan cara :

a. Menyiapkan bak ukur/ mistar monitor untuk memonitor pengangkatan, ditandai dengan garis-garis setiap jarak $5 \mathrm{Cm}$, jumlah. 4 set

b. Menyiapkan material 4 Set gawang angkat (temporary portal support) berupa H Beam 200x200 dan baja Profil C 150, pelat tebal. $12 \mathrm{~mm}$, karung kapasitas $25 \mathrm{~kg}$, jumlah sesuai kebutuhan

c. Menyiapkan mesin las, kawat las, chain block kapasitas. 10 ton, web sling kapasitas. 10 ton

d. Menyiapkan permanent support dan sabowork

e. Memasang temporary support untuk kapasitas angkat. 15 tons, pastikan terpasang dengan baik, aman dan stabil digunakan untuk mengangkat perpipaan

f. Menyiapkan alat komunikasi (radio HT), pluit dan bendera komando, pengangkatan dilakukan dalam satu komando.

2. Cara mengangkat pipa, dengan cara :

a. Melakukan pengukuran elevasi pipa raw water sebelum pengangkatan

b. Memasang chain block, web sling dan sackle clip, sebanyak 4 set untuk pengangkatan pipa

c Mengangkat pipa dengan cara menarik rantai chain block secara bersamaan dengan tinggi/ jarak pengangkatan yang sama

d. Mengangkat pipa dimulai dibagian tengah, pada 2 posisi pipe terendah dengan ketinggian angkat maksimum. $10 \%$ outside diameter (OD) pipa (5 Cm), berhenti sejenak (5-10 menit) sehingga kedua posisi ujung (utara dan selatan) relaksasi dan menyesuaikan e. Mengamati elevasi pipa pada posisi di ke 4 portal dan elevasi portal, catat waktu dan urutan pengangkatan

g. Mengamati permukaan tanah diatas pipa di kedua ujung (utara dan selatan), jika ada indikasi terangkat maka imbangi dengan mengangkat keduanya sampai posisi tenang

h. Mengulangi langkah (c) sampai ketinggian maksimum, ditandai dengan kembalinya elevasi pipa ke elevasi semula atau jika ada indikasi terangkatnya tanah diatas kedua ujung pipa.

3. Metode pemasangan permanent support, dengan cara :

a. Persiapan material baja profil $\mathrm{H}$ Beam 150, Kawat las, semen, pasir, koral, tanah urugan, karung @ $25 \mathrm{~kg}$ sesuai kebutuhan disite

b. Persiapan peralatan, terdiri dari mesin las, chain block kapasitas 10 tons, alat bor tanah dia. $30 \mathrm{Cm}$ dengan kedalaman 2 meter

c. Lakukan pengecoran lubang bor dan lantai kerja dan pastikan mengeras dengan baik

d. Bersihkan longsoran lereng yang menutup area kerja sampai dengan tersedia area kerja aman

k. Pasang sabowork (soil bag/ sandbag) sehingga menopang beam pipe support dengan baik dan aman

1. Letakan pipa diatas beam permanen support

$m$. Ruang antara sabowork dengan dinding Bendali diisi dengan tanah berpasir, ratakan dan padatkan setiap layer $30 \mathrm{Cm}$ dengan elevasi sesuai kebutuhan.

n. Melepas chain block dan web sling, dilakukan setelah semua pekerjaan pengangkatan pipa dan pemasangan permanent support telah selesai dipasang dan beton penumpu permanent support telah dengan baik dan aman 
o. Melepas portal temporary support, dapat dapat dilakukan bila seluruh rangkaian pengangkatan pipa dan pemasangan permanent support telah selesai dan dapat telah dapat berfungsi dengan baik dan aman

p. Pasang tanah urug, ratakan dan padatkan dengan baik tanpa mengganggu stabilitas struktur beton dinding Bendali.

\section{HASIL DAN PEMBAHASAN}

Akibat terjadi kelongsoran lereng maka pipa transmisi raw water unit water treatment plant (Unit WTP) mengalami mengalami pergeseran sejauh $180 \mathrm{Cm}$ dari posisi semula dan terdeformasi sejauh 3 OD pipa. Kondisi ini mengakibatkan pipa raw water pada kondisi sub standard dan unsafe condition.

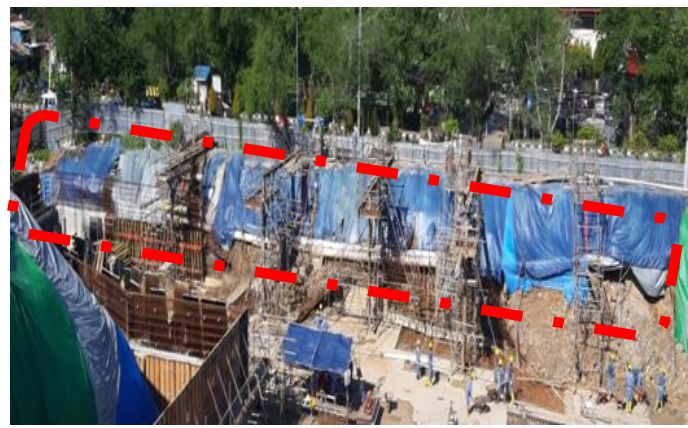

Gambar. 2

Kelongsoran pipa raw water

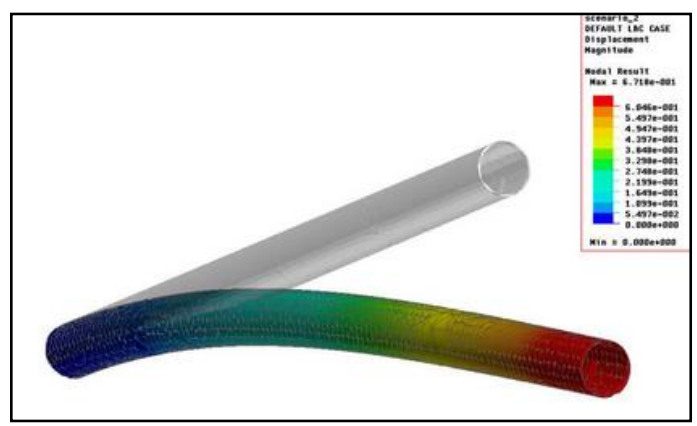

Gambar.3

Stress analysis saat pipa raw water

Setelah pipa raw water mengalami penurunan sejauh $180 \mathrm{Cm}$ dari posisi horizontalitynya (melendut) dan bergeser $60 \mathrm{Cm}$ kearah lateral, hampir semua penampang pipa pada bagian mengali stress (gambar. 3). Hal ini menunjukan bahwa pipa raw water dalam kondisi kritis dan dikawatirkan sewaktu-waktu mengalami kegagalan. Untuk itu maka dipasang penopang sementara disisi bawah pipa dan memasang gawang penggantung pipa serta menggantung pipa raw water dengan websling sebagai tindakan preventif. Untuk mengurangi stress pipa juga dilakukan pengurangan tekanan kerja dan debit (flow) aliran didalam pipa raw water.

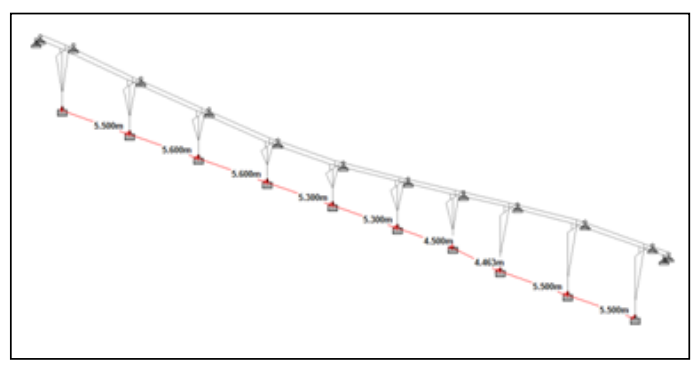

Gambar. 4

Model temporary support

Metode reposisi pipa raw water dilakukan dengan memasang gawang angkat (portal) berbahan dasar steel WF beam 200x200 mm, memasang websling penggantung dan chain block pengangkat kapasitas 20 ton, memasang alat jidar ukur horizontality pipa, menyiapkan alat monitor water pass dan theodolite, data pipe stress analysis, metode kerja, menyiapkan permanent support, menyiapkan sabowork, menyiapkan petugas pengaangkatan dan monitoring. Untuk mencegah terjadi overstress pada saat pengangkat maka selama proses pengangkatan tekanan kerja dan aliran didalam pipa raw water dikondisikan pada minm flow dan low pressure. Dengan kondisi pipa raw water yang telah terdeformasi dan mengalami overstress maka dilakukan pembatasan bahwa reposisi pipa raw water dilakukan secara perlahan dengan sedapat mungkin mencegah terjadinya peningkatan stress pada pipa. Reposisi vertikal dilakukan bertahap setinggi 5 $\mathrm{Cm}$, berhenti 5 menit, monitor kondisi 
horizontality pipa dret han portal pengangkat, lanjut lagi mengangkat setinggi $5 \mathrm{Cm}$, rehat 5 menit, minitor dan memastikan kondisi tumpuan ujung tidak terangkat. Demikian selanjutnya sampai dengan reposisi pipa raw water mencapai elevasi $164 \mathrm{Cm}$ dari kondisi sagingnya. Pada elevasi tersebut reposisi dihentikan karena adanya indikasi deformasi pada portal dan melintirnya websling. Hasil akhir reposisi adalah pipa raw water pada posisi $16 \mathrm{Cm}$ dibawah horizontality awalnya dengan kondisi stress pipa sebagaimana gambar. 5 .
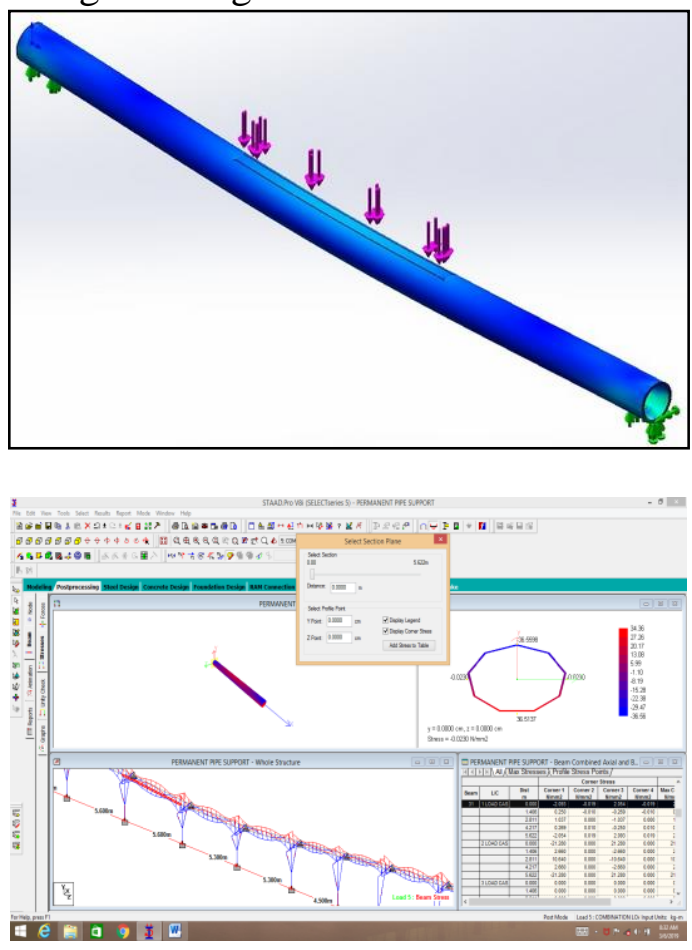

Gambar. 5

Kondisi stress pipa setelah reposisi

Setelah kondisi pipa raw water diperkirakan duduk dengan baik (seatle) selama 2 jam, dilanjutkan dengan pemasangan ajustable permanent support dan sabowork dibawah pipa raw water dan dilanjutkan dengan monitoring harizontality selama 2 hari. Berdasarkan hasil monitoring selama 2 hari posisi horizontality pipa bergerak 4 $\mathrm{Cm}$ kearah atas dan dilanjutkan dengan ajustable permanent support. Gambaran kondisi pipe stress setelah hozontality pipa raw water berada pada elevasi 12 $\mathrm{Cm}$ dibawah horizontality awal (natural) adalah sebagaimana gambar.6.

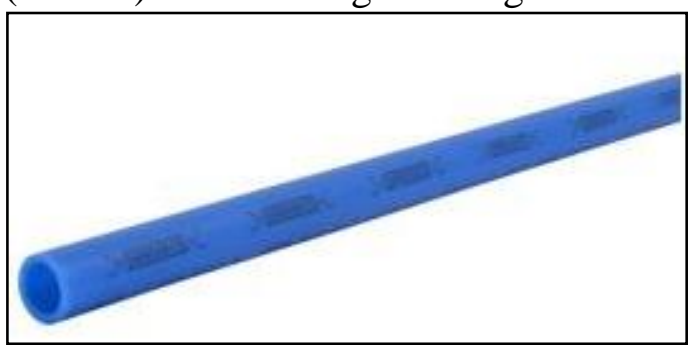

Gambar.6

Kondisi akhir pipa raw water

Tahap awal perhitungan bending stress adalah dengan menghitung momen putar yang terjadi pada pipa dengan persamaan berikut.

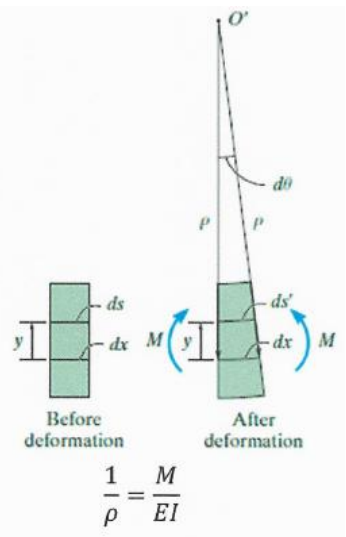

Dengan:

$\rho=$ radius defleksi

$M=$ Momen putar yang menyebabkan pipa terdefleksi

$\mathrm{E}=$ modulus elastisitas material

$\mathrm{I}=$ momen inersia pipa

Momen inersia yang terjadi adalah : 202.961,6 $\mathrm{Inch}^{4}$ atau 0,084478988 $\mathrm{m}^{4}$.

Radius defleksi pipa :

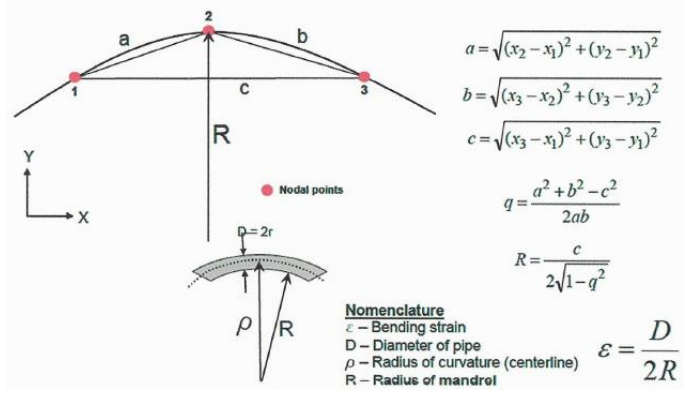

Diperoleh nilai $(\mathrm{a})=19,55 \mathrm{~m}$; $(\mathrm{b})=$ $11,14 \mathrm{~m}$; (c) $=30,69 \mathrm{~m} ;(\mathrm{q})=-0,9959$. Radius defleksi $=169$ meter; Momen putar $=98.997 .634 \mathrm{Nm}$. Sehingga dapat diketahui bending stress pada pipa raw 
water adalah sebesar. 11, $162 \mathrm{Mpa}<$ 435 Mpa, Pipa raw water aman (safe).

\section{KESIMPULAN}

1. Berdasarkan data pipe stress analysis telah terjadi overstress pada pipa raw water, namun tidak sampai melebihi batas yield stress

2. Metode reposisi pipa raw water secara onstream berbasis data stress analysis terbukti cocok dan berhasil dengan baik.

\section{SARAN}

1. Metode stress analysis cocok digunakan untuk analisis material sejenis dan struktur yang mengalami permasalahan sejenis

2. Sucess story aplikasi metode reposisi pipa raw water yang dilakukan pada kondisi onstream dapat direplikasi untuk mengatasi permasalahan sejenis diluar lingkungan Pertamina.

\section{REFERENSI}

[1] Agus Sugianto, Sulardi, (2018), Analisa Tegangan Pipa Transmisi Raw Water Unit WTP Pancur Akibat Kelongsoran Lereng Area Bendali Dahor, RDMP Pertamina RU V, Balikpapan

[2] C. Basavaraju, William S. Sun, (1976), Stress Analysis of Piping, Piping Handbook Chapter B4, Mc Graw Hill Handbook 7th Edition,

[3] Laurence D. Lynch, Charles A.B Bullinger, Alton B. Cleveland, (1976) Piping Layout, Piping Handbook Chapter B3, Mc Graw Hill Handbook 7th Edition,

[4] Lorenzo Di Giacomo Jr, Jon R. Stinson, (1976), Piping Supports, Piping Handbook Chapter B5, Mc Graw Hill Handbook 7th Edition,

[5] Sulardi, (2019), Keselamatan Alat Angkat dan Alat Angkut, Penerbit Nusa Litera Inspirasi, Cirebon, Jawa Barat
[6] Sulardi, (2019), Peralatan Industri, Penerbit Nusa Litera Inspirasi, Cirebon, Jawa Barat

[7] Sulardi, (2019), Investigasi Kejadian, Penerbit Nusa Litera Inspirasi, Cirebon, Jawa Barat

[8] Sulardi, (2017), Reposisi Pipa Transfer Line Flare Stack Dengan Alat Roll Gesenarikan, Jurnal Teknologi B4T (Terakreditasi), Edisi Vol.7 No.2 Desember 2017. 